\title{
The fundamental role of increased production of nitric oxide in lipopolysaccharide-induced embryonic resorption in mice
}

\author{
D. G. Ogando' ${ }^{1}$ D. Paz ${ }^{2}$, M. Cella ${ }^{1}$ and A. M. Franchi ${ }^{1 *}$ \\ ${ }^{1}$ Centro de Estudios Farmacológicos y Botánicos (CEFYBO), Consejo Nacional de Investigaciones \\ Cientificas y Técnicas (CONICET), Serrano 669, Capital Federal, 1414MEM, Buenos Aires, Argentina; \\ and ${ }^{2}$ Instituto de Neurociencia (INEUCI), Departamento de Ciencias Biológicas, Facultad de Ciencias \\ Exactas y Naturales, Universidad de Buenos Aires, Ciudad Universitaria (1428), Buenos Aires, Argentina
}

Nitric oxide (NO) fulfils important functions during pregnancy and has a role in implantation, decidualization, vasodilatation and myometrial relaxation. However, at high concentrations, such as those that are produced in sepsis, NO has toxic effects as it is a free radical. The aim of this study was to characterize uterine and decidual NO production in lipopolysaccharide (LPS)induced embryonic resorption in mice and to determine which isoforms of nitric oxide synthase (NOS) take part. LPS produced $100 \%$ embryonic resorption at $24 \mathrm{~h}$, with complete fetus expulsions at $48 \mathrm{~h}$. Decidual and uterine NO production were increased by LPS, with maximum production at $6 \mathrm{~h}$. This increase was due to the induction of expression of inducible nitric oxide synthase (iNOS) isoform in the decidua and uterus, and neuronal nitric oxide synthase (nNOS) isoform in the decidua, as detected by western blot analysis and immunohistochemistry. LPS increased iNOS expression in decidual and myometrial cells and increased nNOS expression in decidual cells. In addition, LPS caused fibrinolysis and infiltration of mesometrial decidua by macrophages positive for iNOS and CD14 (LPS receptor). Endothelial nitric oxide synthase (eNOS) was found in decidual and uterine arteries but LPS did not modify its expression. LPS induced CD14 expression in endometrial glands, and this could have amplified the inflammatory response. Aminoguanidine, an inhibitor of iNOS activity, totally reversed the LPS-induced embryonic resorption. This result could be explained by an inhibition of the increase in NO production but also by an inhibition of the cellular infiltration and fibrinolysis. These results show that NO fulfils a fundamental role in LPS-induced embryonic resorption.

\section{Introduction}

Nitric oxide (NO) has important roles during pregnancy in implantation, decidualization, vasodilatation of decidual, placental and uterine vessels and myometrial relaxation (Sladek et al., 1997; Chwalisz et al., 1999; Chwalisz and Garfield, 2000). It has also been suggested that NO participates in vascular invasion of the trophoblast (Ariel et al., 1998) and infection control during pregnancy (Nowicki et al., 1997). NO is synthesized from nitric oxide synthase (NOS), of which three isoforms have been identified: neuronal nitric oxide synthase (nNOS), endothelial nitric oxide synthase (eNOS) $\left(\mathrm{Ca}^{2+}\right.$ dependent) and inducible nitric oxide synthase (iNOS) $\left(\mathrm{Ca}^{2+}\right.$-independent). However, at high concentrations, as produced in sepsis, NO has toxic effects as it is a free radical (Grisham et al., 1999). Many of the toxic effects seem to be mediated by peroxinitrite $\left(\mathrm{ONOO}^{-}\right)$, which is produced by the reaction between the superoxide anion $\left(\mathrm{O}_{2}{ }^{-}\right)$and NO. Peroxinitrite is not a free radical but is

*Correspondence

Email: afranchi@mail.retina.ar a more powerful oxidant than NO, as it is less sensitive to the action of antioxidant enzymes (Grisham et al., 1999). The toxic effects of NO include: inhibition of the mitochondrial respiratory chain, lipid peroxidation (damage to the cellular membrane), protein and nucleic acid nitration, DNA break, vascular injury, necrosis and apoptosis (Karima et al., 1999). During early pregnancy in mice, the implantation sites are highly sensitive to proinflammatory molecules such as lipopolysaccharide (LPS) and Th1 cytokines such as gamma interferon (IFN$\gamma)$, tumour necrosis factor $\alpha(\mathrm{TNF}-\alpha)$ and interleukin 2 (IL-2) are capable of producing embryonic resorption (Chaouat et al., 1990; Raghupathy, 1997).

Relatively low doses of LPS that do not endanger the survival of the mother produce high percentages of embryonic resorption (Gendron et al., 1990). In the spontaneous abortion murine model $(\mathrm{CBA} \times \mathrm{DBA}$ crosses), early infiltration of the decidua with macrophages expressing iNOS has been demonstrated (Haddad et al., 1995). In addition, the percentage of implantation sites pre-activated for $\mathrm{NO}$ production coincides with the percentage of embryonic resorption (Haddad et al., 1995; Duclos et al., 1996). It has been demonstrated 
in the same model that $\mathrm{NO}$ is fundamental to the resorption process, as aminoguanidine, an inhibitor of the iNOS isoform activity (Misko et al., 1993), partially inhibits resorption (Haddad et al., 1995; Athanassakis et al., 1999). However, the NOS isoforms and the cells that express them have not been characterized. Therefore, the aim of the present study was to characterize NO production and the NOS isoforms expressed in implantation sites in normal pregnancy and in LPS-induced embryonic resorption.

\section{Materials and Methods}

\section{Reagents}

LPS of Escherichia coli 05:B55, aminoguanidine, nitrate reductase, lactate dehydrogenase, secondary alkaline phosphatase conjugated antibodies, nitrocellulose membranes and $p$-xylene-bis ( $\mathrm{N}$-pyridinium bromide) (DPX) were purchased from Sigma Chemical Co. (St Louis, MO); $\left[{ }^{14} \mathrm{C}\right]$ arginine was purchased from Amersham Corporation (Arlington Heights, IL). Dowex AG 50W-X8 cation exchange resin was obtained from Bio-Rad Laboratories (Tecnolab SA, Buenos Aires). The western blotting reagents were obtained from Sigma and Bio-Rad. The anti-iNOS antibody was obtained from Santa Cruz Biotechnology (Santa Cruz, CA). The antieNOS and anti-nNOS antibodies and positive controls were obtained from BD Transduction Laboratories (Lexington, KY); CSA/HRP kit and preimmune sera were purchased from Dako Corporation (Carpinteria, CA). All other chemicals were of analytical grade.

\section{Animals and treatments}

$\mathrm{BALB} / \mathrm{c}$ 8- to 12-week-old virgin female mice were paired with 8- to 12-week-old BALB/C males, and the day of appearance of a coital plug was taken as day 0 of pregnancy. Animals received food and water ad libitum and were exposed to a $12 \mathrm{~h}$ light: $12 \mathrm{~h}$ dark cycle. Mice were killed by cervical dislocation. Animals were cared for in accordance with the principles and guidelines of the Guide for the Care and Use of Laboratory Animals (US National Research Council, 1996).

\section{Effect of aminoguanidine on LPS-induced embryonic resorption (Experiment 1)}

Pregnant mice were divided into four groups: (i) control: females received an i.p. injection of vehicle (PBS) on days 6 and 7 of pregnancy. (ii) aminoguanidine: females received an i.p. injection of $6 \mathrm{mg}$ aminoguanidine per mouse on day 6 (09:00 h) of pregnancy and a second i.p. injection of $6 \mathrm{mg}$ aminoguanidine on day 7 (09:00 h), and $4 \mathrm{~h}$ later were administered another i.p. injection of $6 \mathrm{mg}$ aminoguanidine. (iii) LPS: females received an i.p. injection of PBS on day 6 (09:00 h) of pregnancy, an i.p. injection of $0.5 \mu \mathrm{g}$ LPS per g body weight on day 7 (09:00 h), and $4 \mathrm{~h}$ later were administered another i.p. injection of PBS. (iv) LPS plus aminoguanidine: females received an i.p. injection of $6 \mathrm{mg}$ aminoguanidine per mouse on day 6 (09:00 h) of pregnancy, an i.p. injection of $0.5 \mu \mathrm{g}$ LPS per g body weight on day 7 (09:00 h) plus an i.p. injection of $6 \mathrm{mg}$ aminoguanidine, and $4 \mathrm{~h}$ later were administered another i.p injection of $6 \mathrm{mg}$ aminoguanidine. Animals were killed on day 8 or 12 of pregnancy and fetal resorption rates were calculated. Eight animals $(n=8)$ per group were used in this experiment.

\section{Effect of nitrate and nitrite production (Experiment 2)}

On day 7 (09:00 h) of pregnancy, females were injected i.p. with vehicle (PBS) or $0.5 \mu \mathrm{g}$ LPS per g body weight. Mice were killed by cervical dislocation at 0,2 , 6,12 and $24 \mathrm{~h}$ after injection. In each implantation site, the uterus and decidua were separated and incubated separately for $24 \mathrm{~h}$. $\mathrm{NO}$ as $\mathrm{NO}_{3}{ }^{-}$plus $\mathrm{NO}_{2}{ }^{-}$was measured in supernatants. Six animals $(n=6)$ per time point were used.

\section{Histology, immunodetection of NOS isoforms and CD14, and NOS activity (Experiment 3)}

Pregnant mice were divided into four groups and treated as described in Expt 1, except that animals were killed $6 \mathrm{~h}$ after LPS injection. In each implantation site, the uterus and decidua were separated and immediately frozen at $-70^{\circ} \mathrm{C}$. These tissues were used to measure NOS activity and for iNOS, eNOS, nNOS and CD14 detection by western blot analysis. Freshly removed implantation sites from the same animals were fixed in $4 \%$ paraformaldehyde for iNOS, eNOS, nNOS and CD14 detection by immunohistochemistry and for haematoxylin-eosin staining. Six animals per group were used in this experiment. The effect of aminoguanidine in LPS-induced leucocyte infiltration was studied. Haematoxylin-eosin-stained sections for the four groups were scored for the density of leucocytes by counting ten fields $(1000 \times$ objective $)$ pooled from the mesometrial decidua of each implantation site. Ten animals were used per treatment, and three sites of implantation of each animal were randomly selected. Haematoxylineosin staining of sites of LPS-treated and control animals at $24 \mathrm{~h}$ after injection was performed. Granulocytes, macrophages and large granular lymphocytes (LGLs) were distinguished by morphology. Macrophages and granulocytes are CD14 positive and the presence of LGLs was confirmed by PAS staining.

\section{Cultures of implantation sites}

Uterine and decidual tissues were weighed and individually cultured in wells that contained $330 \mu \mathrm{l}$ DMEM (GIBCO, Rockville, MD) supplemented with $10 \%$ 
FCS (GIBCO) and antibiotics: 20 iu penicillin $\mathrm{G} \mathrm{ml}^{-1}$, $20 \mu \mathrm{g}$ streptomycin $\mathrm{ml}^{-1}$ and $50 \mathrm{ng}$ amphotericin $\mathrm{B} \mathrm{ml}^{-1}$ (GIBCO). Explants were maintained for $24 \mathrm{~h}$ in $5 \% \mathrm{CO}_{2}$ in air at $37^{\circ} \mathrm{C}$. Supernatants were obtained to measure $\mathrm{NO}_{3}{ }^{-}$and $\mathrm{NO}_{2}{ }^{-}$.

\section{Nitrate and nitrite assay}

$\mathrm{NO}$ produced by tissues was measured as nitrate $\left(\mathrm{NO}_{3}{ }^{-}\right)$and nitrite $\left(\mathrm{NO}_{2}{ }^{-}\right)$in the culture supernatant, using the technique described by Grisham et al. (1996). Briefly, $100 \mu \mathrm{l}$ of supernatants, $5 \mu \mathrm{l}$ of $2 \mathrm{mmol} \mathrm{NADPH} \mathrm{I} \mathrm{I}^{-1}$ and $5 \mu \mathrm{l}$ of Aspergillus (10 U nitrate reductase $\mathrm{ml}^{-1}$ ) were allowed to react in flatbottomed 96-well culture plates with gentle mixing for $30 \mathrm{~min}$ at room temperature. Next, $10 \mu \mathrm{l}$ of $100 \mathrm{mmol}$ pyruvic acid $\mathrm{I}^{-1}$ and $10 \mu \mathrm{l}$ of $1000 \mathrm{U}$ lactate dehydrogenase $\mathrm{ml}^{-1}$ were added and incubated for $10 \mathrm{~min}$. Later, $50 \mu \mathrm{l}$ of $10 \mathrm{mg}$ sulphanilic acid $\mathrm{ml}^{-1}$ was added and incubation continued for $10 \mathrm{~min}$. Finally, $50 \mu \mathrm{l}$ of $1 \mathrm{mg}$ naphthyl-ethylenediamine $\mathrm{ml}^{-1}$ was added and incubated for $5 \mathrm{~min}$ in the dark. The absorbance of the coloured product was measured at $540 \mathrm{~nm}$, using $670 \mathrm{~nm}$ readings as reference wavelength to compensate for non-specific absorbance. Media supplemented with fetal calf serum were cultured without any tissue and used as a blank. The concentration of $\mathrm{NO}_{3}{ }^{-}$and $\mathrm{NO}_{2}{ }^{-}$was deduced from a standard nitrate curve. Results were expressed as $\mu \mathrm{mol}$ per $100 \mathrm{mg}$ wet weight.

\section{Determination of NOS activity}

A modification of the method of Bredt and Snyder (1989) was used to determine NO release from incubated decidua and uterine strips. This method measures the conversion of $\left[{ }^{14} \mathrm{C}\right]$ arginine to $\left[{ }^{14} \mathrm{C}\right]$ citrulline, as citrulline remains in the sample, whereas the equimolar amounts of NO produced are rapidly destroyed. Briefly, slices of tissue were incubated at $37^{\circ} \mathrm{C}$ in a buffer containing $20 \mathrm{mmol}$ Hepes $\mathrm{I}^{-1}, 10 \mu \mathrm{mol}\left[{ }^{14} \mathrm{C}\right]$ arginine $\mathrm{I}^{-1}(0.3 \mu \mathrm{Ci}), 25 \mathrm{mmol}$ valine $\mathrm{I}^{-1}, 1 \mathrm{mmol}$ DTT $\mathrm{I}^{-1}$, $0.45 \mathrm{mmol} \mathrm{CaCl}_{2} \mathrm{I}^{-1}$ and $1 \mathrm{mmol} \mathrm{NADPH} \mathrm{I^{-1 }}$. Valine, which inhibits the conversion of L-arginine to L-citrulline by arginases, was included in the reaction mixture to increase assay specificity. The samples were homogenized after $15 \mathrm{~min}$ of incubation, centrifuged for $10 \mathrm{~min}$ at $3000 \mathrm{~g}$ and applied to a $1 \mathrm{ml}$ DOWEX AG50WX8 column $\left(\mathrm{Na}^{+}\right.$form) and $\left[{ }^{14} \mathrm{C}\right]$ citrulline was eluted in $3 \mathrm{ml}$ water. The radioactivity was measured by liquid scintillation counting. Enzyme activity is reported as pmol $\left[{ }^{14} \mathrm{C}\right]$ citrulline per $15 \mathrm{~min}$ per $100 \mathrm{mg}$ wet weight.

\section{Western blot analysis}

The tissues were homogenized in an Ultra-Turrax homogenizer in a $20 \mathrm{mmol}$ Tris buffer $\mathrm{I}^{-1}(\mathrm{pH} 7.4)$ containing $0.25 \mathrm{mmol}$ sucrose $\mathrm{I}^{-1} ; 10 \mu \mathrm{g}$ aprotinin $\mathrm{ml}^{-1} ; 10 \mu \mathrm{g}$ leupeptin $\mathrm{ml}^{-1} ; 1 \mathrm{mg}$ benzamidine $\mathrm{ml}^{-1}$; $1 \mathrm{mg}$ caproic acid $\mathrm{ml}^{-1} ; 10 \mu \mathrm{g}$ soybean trypsinogen inhibitor $\mathrm{ml}^{-1}$; and 1 mol EDTA $\mathrm{I}^{-1}$. Next, samples were sonicated. After centrifugation at $7800 \mathrm{~g}$ for $10 \mathrm{~min}$, the supernatants were collected and stored at $-70^{\circ} \mathrm{C}$ until western blotting was performed. Each point represented pooled material from six animals. The experiment was repeated three times using different pooled materials from six animals each time, making a total of 18 animals per treatment. One hundred micrograms of protein was loaded in each lane. Positive control aliquots were also loaded: the membrane fraction of human endothelial cells was used for eNOS; mouse macrophage lysate was used for iNOS and CD14; and rat pituitary lysate was used for nNOS (BD Transduction Laboratories). Samples were separated on $7.5 \%(\mathrm{w} / \mathrm{v})$ sodium dodecyl sulphate-polyacrylamide gel by electrophoresis and transferred to a nitrocellulose membrane (Sigma). The blots were incubated overnight at $4{ }^{\circ} \mathrm{C}$ with the primary antibodies diluted $1: 1000$ in blocking buffer. The primary antibodies were anti-iNOS rabbit polyclonal (Santa Cruz Biotechnology), anti-eNOS and anti-nNOS mouse monoclonals (BD Transduction Laboratories). The blots were washed with buffer $\left(10 \mathrm{mmol}\right.$ Tris $\mathrm{I}^{-1}$, $100 \mathrm{mmol} \mathrm{NaCl} \mathrm{I} \mathrm{I}^{-1}$ and $0.1 \%(\mathrm{v} / \mathrm{v})$ Tween 20, $\mathrm{pH}$ 7.5) followed by alkaline phosphatase-conjugated antirabbit or anti-mouse IgG as the secondary antibody, and developed with 5-bromo-4-chloro-3-indolyl-phosphate toluidine salt and nitroblue tetrazolium. Molecular weight markers and positive controls were run in each blot to identify the protein bands. Photographs of the membranes were scanned using a UMAX Astra $1220 \mathrm{~S}$ scanner and analysed in a densitometer using a Sigma Gel software package. The concentration of protein loaded in each lane was measured by the method of Bradford (1976).

\section{Immunohistochemistry}

Freshly removed implantation sites were fixed in $4 \%$ paraformaldehyde overnight at $4{ }^{\circ} \mathrm{C}$. The tissues were embedded in paraffin wax and sections of $4 \mu \mathrm{m}$ were cut and placed on silanized glass slides. Sections that passed through the centre of the implantation site were selected. The immunoperoxidase staining kit CSA/HRP (Dako) was used according to the protocol recommended by the manufacturer. Briefly, tissue sections were de-paraffinized, rehydrated in buffer and blocked in blocking buffer. Endogenous peroxidase activity of the tissues was quenched with $0.1 \%$ hydrogen peroxide in water for $50 \mathrm{~min}$. The sections were incubated overnight at $4{ }^{\circ} \mathrm{C}$ with the primary antibodies diluted $1: 1000$ in blocking buffer. The primary antibodies were anti-iNOS and anti-CD14 rabbit polyclonal (Santa Cruz Biotechnology), anti-eNOS and anti-nNOS mouse monoclonal (BD Transduction 
Table 1. Effect of aminoguanidine (AG) on lipopolysaccharide (LPS)-induced embryonic resorption in mice

\begin{tabular}{|c|c|c|c|}
\hline Treatment* & $\begin{array}{l}\text { Number of animals that expulsed } \\
\text { embryos at day } 9\end{array}$ & $\begin{array}{l}\text { Number of implantation } \\
\text { sites per mouse }\end{array}$ & Resorption rate $(\%)$ \\
\hline Control $^{\dagger}$ & - & $11.1 \pm 0.8$ & 0 \\
\hline $\mathrm{AG}^{\dagger}$ & - & $10.0 \pm 0.6$ & 0 \\
\hline $\mathrm{LPS}^{\dagger}$ & - & $9.9 \pm 0.4$ & $100^{b}$ \\
\hline $\mathrm{LPS}+\mathrm{AG}^{\dagger}$ & - & $10.4 \pm 0.6$ & $0^{c}$ \\
\hline Control $^{\ddagger}$ & 0 & $11.4 \pm 0.2$ & $10.8 \pm 2.3$ \\
\hline $\mathrm{AG}^{\ddagger}$ & 0 & $11.0 \pm 0.9$ & $7.5 \pm 2.1$ \\
\hline LPS $\ddagger$ & 7 & $0^{\mathrm{a}}$ & $100^{d}$ \\
\hline $\mathrm{LPS}+\mathrm{AG}^{\ddagger}$ & 0 & $11.4 \pm 0.5$ & $17.5 \pm 12.2^{\mathrm{e}}$ \\
\hline
\end{tabular}

$* n=8$ for each treatment.

${ }^{\dagger}$ Killed at day 8.

$\ddagger$ Killed at day 12 .

Protocol corresponds to Expt 1. Briefly, BALB/c females were injected on day 6 or day 7 of pregnancy with PBS (control), AG, LPS or LPS plus AG and killed at day 8 or day 12 of pregnancy. Embryonic resorption rates were calculated using the formula: $100 \times$ resorbing embryos/(viable plus resorbing embryos). Values are mean \pm

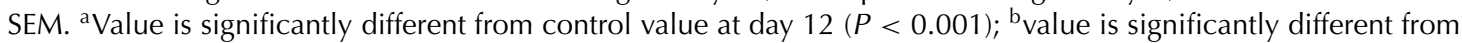
control value at day $8(P<0.001)$; ${ }^{c}$ value is significantly different from value for LPS-treated mice at day $8(P<$ $0.001) ;{ }^{d}$ value is significantly different from control value at day $12(P<0.001)$; ${ }^{\mathrm{e}}$ value is significantly different from value for LPS-treated mice at day $12(P<0.001)$.

Laboratories). Control sections without primary antibody or with pre-immune rabbit or mouse serum (Dako) were made. Biotinylated secondary anti-mouse or antirabbit antibodies were added and the sections incubated for $15 \mathrm{~min}$. The sections were then incubated with streptavidine-biotin complex for $15 \mathrm{~min}$. Later, biotiniltyramide amplification reagent was added and the sections were incubated for $15 \mathrm{~min}$. Between each step, sections were washed for $5 \mathrm{~min}$ in $0.05 \mathrm{~mol}$ Tris $\mathrm{I}^{-1}$ buffer containing $0.3 \mathrm{~mol} \mathrm{NaCl} \mathrm{I}^{-1}$ and $0.1 \%(\mathrm{v} / \mathrm{v})$ Tween 20. Finally, streptavidine-peroxidase was added and incubated for $15 \mathrm{~min}$. Diaminobenzidine was used as the peroxidase substrate, and the tissue sections were counterstained with haematoxylin. The sections were covered with DPX (Sigma).

\section{Statistical analysis}

Statistical significance was determined by ANOVA and Student-Newman-Keuls multiple comparison test for unequal replicates. A $P$ value $<0.05$ was considered significant.

\section{Results}

\section{Effect of aminoguanidine on LPS-induced embryonic resorption (Experiment 1)}

LPS produced $100 \%$ embryonic resorption at $24 \mathrm{~h}$ after injection (Table 1). The implantation sites from LPStreated females were totally expelled by the mother on day 9. No evidence of gestation was found on day 12 . Aminoguanidine inhibited the LPS-induced embryonic resorption studied on days 8 and 12 (day 8, LPS 100\% versus LPS plus aminoguanidine $0 \%, P<0.001$; day 12 , LPS $100 \%$ versus LPS plus aminoguanidine $17.5 \pm$
$11.2 \%, P<0.001)$. All the LPS-treated females expelled their fetuses on day 9. None of the LPS plus aminoguanidine-treated females expelled their fetuses; all delivered normal, live fetuses. These results indicate that LPS treatment induces embryonic resorption via an increase in $\mathrm{NO}$ production. In control animals, aminoguanidine did not affect the resorption percentage or the number of implantation sites when observed on days 8 and 12 . In addition, aminoguanidine did not have any effect on the size and morphology of the embryos or the weight of the placenta (data not shown). All the female mice treated with aminoguanidine delivered normal, live fetuses.

\section{Effect of $\mathrm{LPS}$ on $\mathrm{NO}_{3}{ }^{-}$and $\mathrm{NO}_{2}{ }^{-}$production (Experiment 2)}

In the decidua of control animals, a low production of $\mathrm{NO}$ (measured as $\mathrm{NO}_{3}{ }^{-}$plus $\mathrm{NO}_{2}{ }^{-}$) was observed at 0 and $2 \mathrm{~h}$ after vehicle injection (Fig. $1 \mathrm{a}$ ). NO production increased at $6 \mathrm{~h}(P<0.05)$ and remained high at $24 \mathrm{~h}$ $(P<0.05)$. Thus, there is a physiological change in decidual NO production during day 7 of pregnancy. In decidua, LPS treatment produced a significant increase in NO production, at $2(P<0.05), 6(P<0.05)$ and $12 \mathrm{~h}(P<0.05)$ after injection (Fig. 1a), with production highest at $6 \mathrm{~h}$. However, at $24 \mathrm{~h}$ after LPS injection, NO production was undetectable and was thus lower than in the control $(P<0.05)$. In control animals, no variations in uterine $\mathrm{NO}$ production were observed during days 7 and 8 of pregnancy (Fig. 1b). LPS produced a significant increase in NO production in the uterus at $6(P<0.05)$, $12(P<0.05)$ and $24 \mathrm{~h}(\mathrm{P}<0.05)$ after injection, reaching a maximum at $6 \mathrm{~h}$ (Fig. $1 \mathrm{~b}$ ). 


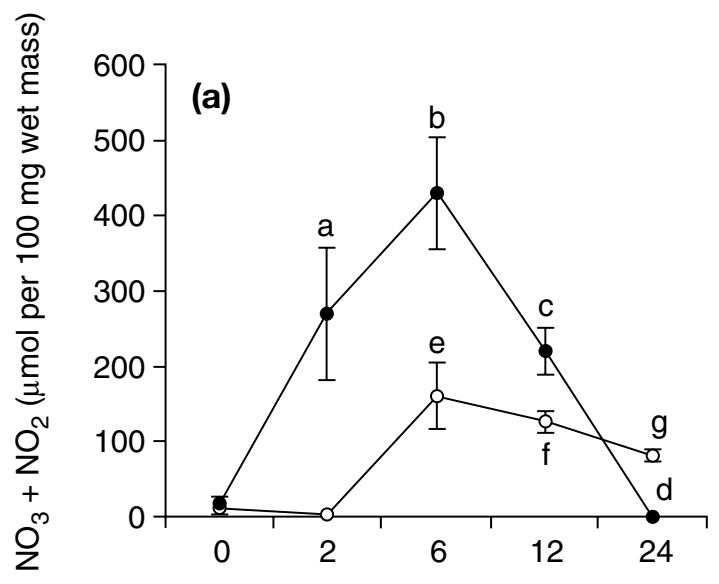

Time (h) after infection with PBS or LPS



Fig. 1. Temporal curve of $\mathrm{NO}_{3}{ }^{-}$plus $\mathrm{NO}_{2}{ }^{-}$production for (a) decidua and (b) uterine explants of mice injected with PBS (control) $(\bigcirc ; n=6)$ or lipopolysaccharide (LPS) $(\bullet ; n=6)$. Values are mean $\pm \operatorname{SEM}(n=6)$. Briefly, females were killed at different times after injection of LPS or PBS. In each site of implantation, the uterus and decidua were separated and incubated for $24 \mathrm{~h}$. $\mathrm{NO}_{3}{ }^{-}$plus $\mathrm{NO}_{2}{ }^{-}$concentrations were measured in supernatants by Greiss reaction. (a) ${ }^{a-d}$ Values are significantly different from decidua control values $(P<0.05)$; ${ }^{\mathrm{e}-\mathrm{g}}$ values are significantly different from decidua control values at $0 \mathrm{~h}(P<0.05)$. (b) ${ }^{\mathrm{a}-\mathrm{c}}$ Values are significantly different from uterine control values $(P<0.05)$.

\section{Histology after treatments (Experiment 3)}

In control animals (PBS) on day 8 of pregnancy, the embryo, trophoblast and decidua with abundant lacunae were observed (Fig. 2a). In animals treated with LPS on day 7 of pregnancy, the decidua near the embryo was totally necrotized with some cellular debris on day 8 (24 h after injection) (Fig. 2b,c). This zone of the decidua was joined to the uterus by a small piece of tissue which was expelled on day 9 (Fig. 2b). Part of the decidua, closer to the uterus, was highly infiltrated by granulocytes and LGLs (Fig. 2d), which probably direct the expulsion of the necrotized decidua, fibrinolysis and tissue regeneration.
Table 2. Effect of aminoguanidine (AG) on lipopolysaccharide (LPS)-induced leucocyte infiltration in mice

\begin{tabular}{lcc}
\hline Treatment* & $\begin{array}{c}\text { Number of implantation } \\
\text { sites analysed }\end{array}$ & $\begin{array}{c}\text { Number of leucocytes } \\
\text { per field }\end{array}$ \\
\hline Control & 30 & $6.1 \pm 1.8$ \\
AG & 30 & $5.8 \pm 1.5$ \\
LPS & 30 & $71.8 \pm 9.3^{\mathrm{a}}$ \\
LPS + AG & 30 & $31.7 \pm 12.8^{\mathrm{b}}$ \\
\hline
\end{tabular}

$* n=10$ for each treatment.

Briefly, BALB/C females were injected on day 6 or day 7 of pregnancy with PBS (control), AG, LPS or LPS plus AG, and killed $6 \mathrm{~h}$ after injection. Entire sites of implantation were fixed and stained with haematoxylin-eosin. Stained sections were scored for the density of leucocytes by counting ten fields $(1000 \times$ objective $)$ pooled from the mesometrial decidua of each implantation site. Three sites of implantation of each animal were selected ran-

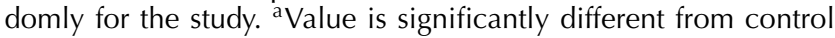
$(P<0.01)$; ${ }^{b}$ value is significantly different from LPS-treated mice $(P<0.05)$.

Histological differences between treatments (Table 1) at the time of maximum $\mathrm{NO}$ production $(6 \mathrm{~h}$ after injection of LPS) were determined. Large lacunas in the mesometrial deciduas of control animals were observed (Fig. 3a,c). Six hours after injection, LPS produced high fibrinolysis and infiltration of the mesometrial decidua (Fig. 3e,g). The infiltrates were identified as macrophages and granulocytes by morphology and CD14 positivity (Fig. $7 d$ inset), and because they were identified in the mesometrial decidua (Table 2). Aminoguanidine treatment significantly inhibited LPS-induced infiltration $(P<0.05)$ (Table 2$)$ and fibrinolysis (Fig. $3 \mathrm{f}, \mathrm{h})$ and this could explain the inhibitory effect of aminoguanidine on embryonic resorption. Aminoguanidine treatment alone did not induce any visible morphological changes (Fig. 3b,d).

\section{Immunodetection of NOS isoforms and CD14 (Experiment 3)}

NOS isoforms and CD14 present at the time of the highest production of $\mathrm{NO}$ ( $6 \mathrm{~h}$ after injection) were also analysed. A considerable increase in iNOS expression could be detected by western blot analysis in the uterus and decidua after LPS treatment $(P<0.05)$ (Fig. 4a,b). Surprisingly, LPS augmented nNOS isoform expression in the decidua but not in the uterus $(P<0.05)$ (Fig. 4c,d). No variations in eNOS expression by LPS were observed in the uterus and decidua (Fig. 4e,f). The treatment with aminoguanidine did not affect NOS isoform expression in the control or LPS-treated animals (Fig. $4 b, d, f)$, indicating that the inhibition of infiltration and fibrinolysis caused by aminoguanidine is not accompanied by inhibition of NOS isoform expression. In the sites of implantation, the expression of CD14 was detected by western blot analysis as a $54 \mathrm{kDa}$ band in the tissues and positive control. The 

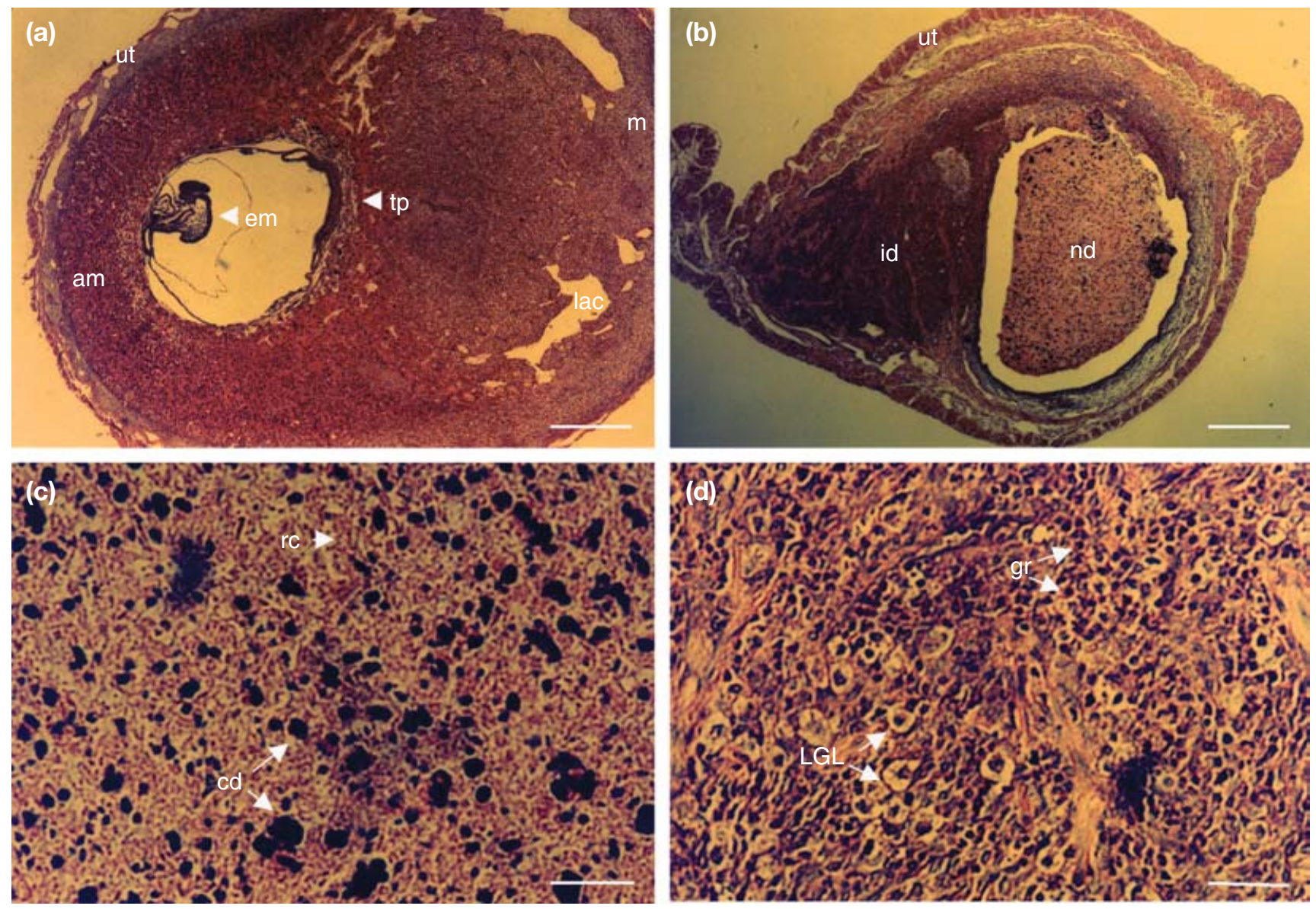

Fig. 2. Effect of lipopolysaccharide (LPS) on implantation sites in mice at $24 \mathrm{~h}$. Briefly, BALB/c female mice were injected on day 7 of pregnancy with $0.5 \mu \mathrm{g}$ LPS or PBS (control) per g body weight and killed $24 \mathrm{~h}$ later. Sections of implantation sites were obtained and stained with haematoxylin-eosin. (a) In the control animal implantation chamber (day 8 of pregnancy), embryo (em), trophoblast (tp) and abundant decidual lacunas (lac) were observed. (b) An advanced grade of resorption in LPS-treated mice was observed. In the decidua of LPS-treated animals, two zones were distinguished: one necrotic decidua (nd) that possesses only cellular debris (c); and one infiltrated decidua (id), containing granulocytes and large granular lymphocytes (d). am: antimesometrial decidua; cd: cellular debris; gr: granulocytes; LGL: large granular lymphocytes; m: mesometrial decidua; rc: red cells; ut: uterus. Scale bars represent (a,b) $380 \mu \mathrm{m}$ and $(\mathrm{c}, \mathrm{d}) 50 \mu \mathrm{m}$.

expression of CD14 was high in the decidua and was not regulated by aminoguanidine or LPS (Fig. 4g,h). This high expression could explain the increased sensitivity of the decidua to LPS. The expression of CD14 in the uterus was lower but was increased by LPS treatment $(P<$ 0.05) (Fig. 4g,h). The LPS-increased CD14 expression in the uterus may be related to an amplification of the inflammatory response. Western blot analysis did not detect any differences in NOS expression between control and aminoguanidine, or between LPS and LPS plus aminoguanidine. Therefore, only control and LPS treatments were processed by immunohistochemistry. In control animals (on day 7 of pregnancy) a light staining for iNOS was observed in decidual cells and in the muscular cells of the myometrium (Fig. 5a,c,e). LPS treatment produced a considerable increase in iNOS expression in cells of the antimesometrial decidua (Fig. 5b,d) and muscular cells of the myometrium (Fig. 5f). In addition the mesometrial decidua had extensive fibrinolysis and infiltration of iNOS positive macrophages and granulocytes (Fig. 5h). In control animals (on day 7 of pregnancy) a moderate staining for $\mathrm{nNOS}$ was found in decidual cells. The staining was minimal in the uterus (Fig. 6e,g). LPS treatment resulted in a considerable increase in nNOS expression in decidual cells but not in the uterus (Fig. 6f,h). This observation correlates with western blot analysis results. eNOS was present in the endothelium of the decidual lacunes and uterine blood vessels in control and LPS-treated animals (Fig. 6a,b). No difference in the staining for eNOS was observed between control and LPS-treated mice (Fig. 6c,d). In control animals (on day 7 of pregnancy), CD14 expression was low in decidual cells, endometrial glands and myometrial cells (Fig. 7a,c). LPS treatment produced a considerable 

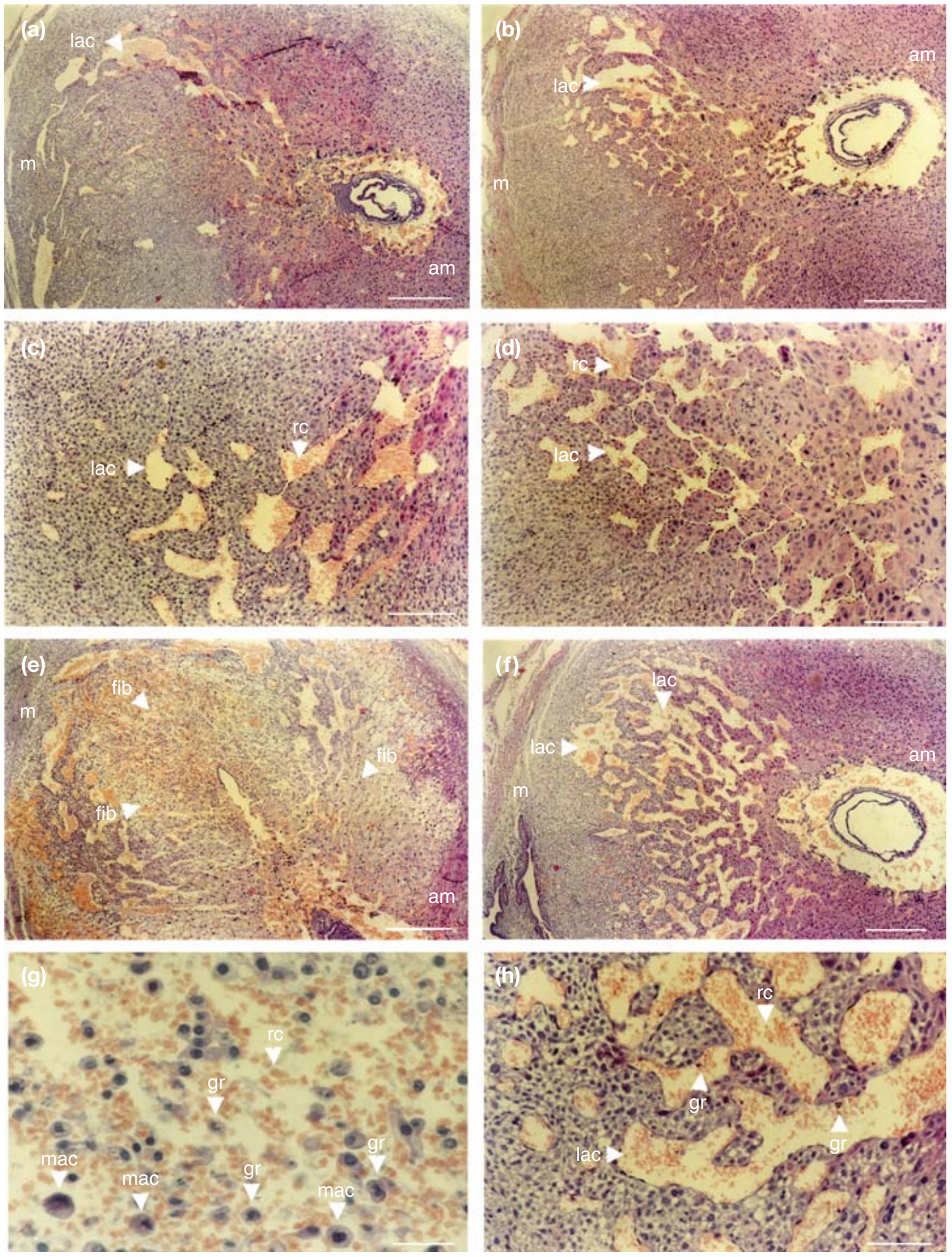

Fig. 3. Histology of different treatments in mice. Briefly, BALB/c female mice were injected on day 6 or day 7 of pregnancy with PBS (control), aminoguanidine, lipopolysaccharide (LPS) or LPS plus aminoguanidine, and killed $6 \mathrm{~h}$ after injection. Entire sites of implantation were fixed and sections were stained with haematoxylin-eosin. (a) Low power view of control site, showing large lacunas (lac) in mesometrial decidua (m). (b) Low power view of aminoguanidine-treated animals, with similar morphology to control. (c,d) Details of decidual lacunas of control and aminoguanidine-treated animals, respectively. (e,g) LPS produced high fibrinolysis (fib) and infiltration of mesometrial decidua. The infiltrates were identified as granulocytes (gr) and macrophages (mac). (f,h) Aminoguanidine inhibits infiltration and fibrinolysis produced by LPS. am: antimesometrial decidua; rc: red cells. Scale bars represent $(a, b) 200 \mu m,(c, d) 100 \mu m,(e, f)$ $160 \mu \mathrm{m}$ and $(\mathrm{g}, \mathrm{h}) 80 \mu \mathrm{m}$. 
(a) Decidua

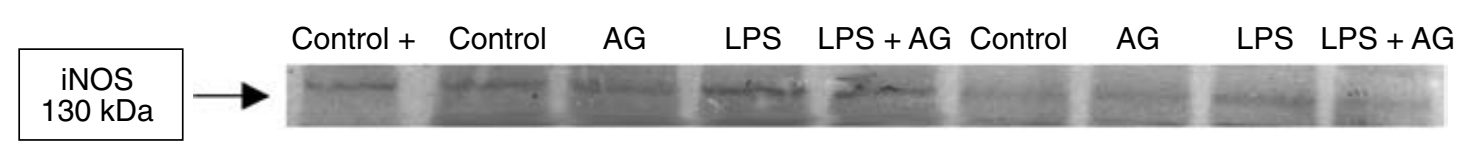

(b)

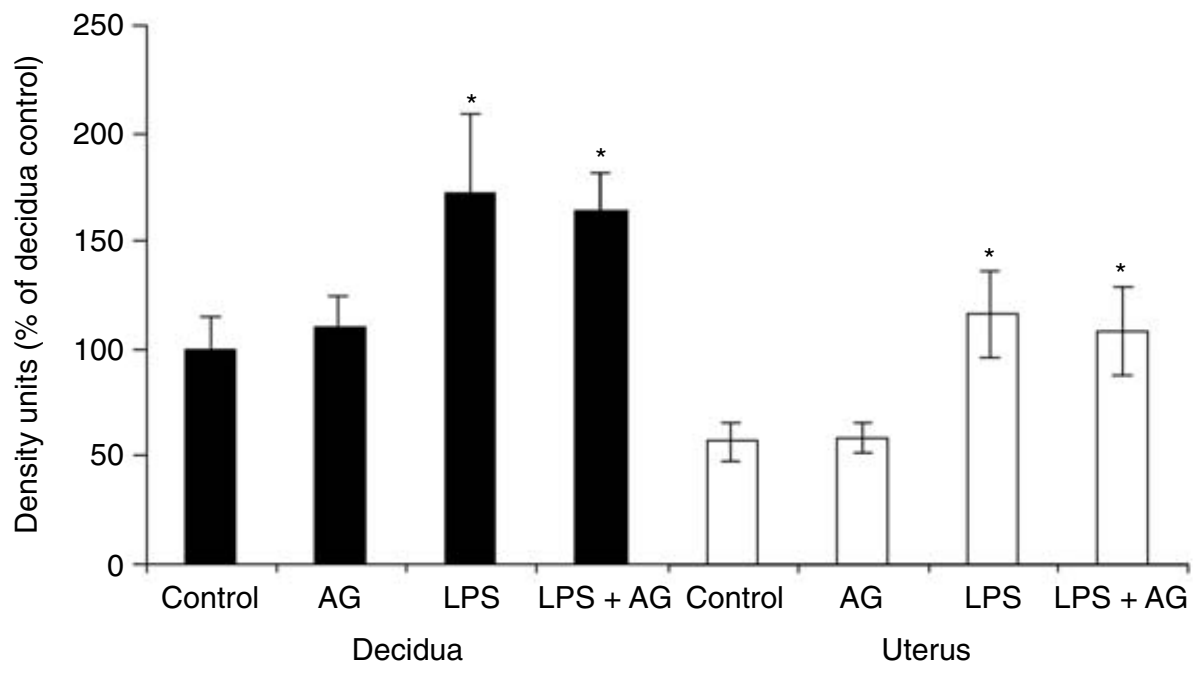

(c)

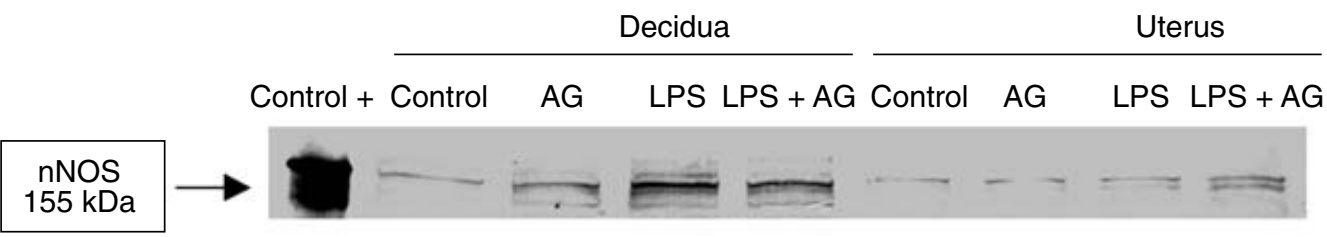

(d)

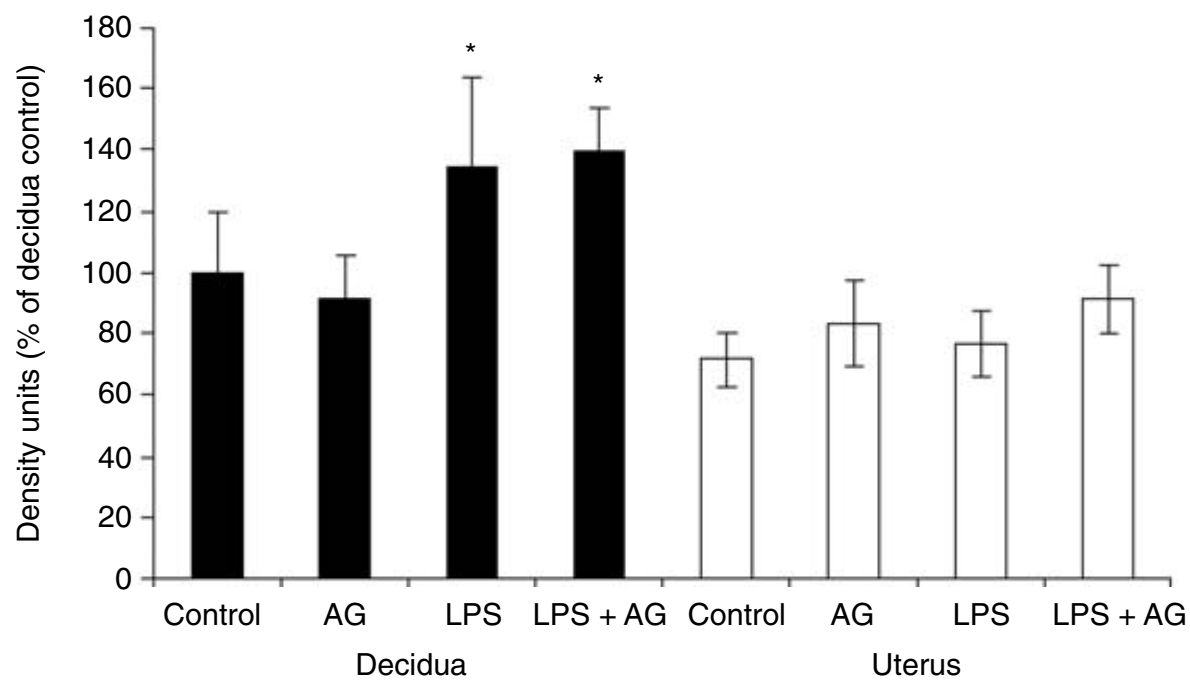

Fig. 4. Western blot analysis in mice using polyclonal antibodies (a) anti-iNOS (inducible nitric oxide synthase) and (g) anti-CD14 (LPS receptor); and monoclonal antibodies (c) anti-nNOS (neuronal nitric oxide synthase) and (e) anti-eNOS (endothelial nitric oxide synthase). Samples were homogenates of the decidua and uteri of mice from different treatments. Briefly, BALB/c female mice were injected on day 6 or day 7 of pregnancy with PBS (control), aminoguanidine (AG), lipopolysaccharide (LPS) or LPS plus AG, and killed $6 \mathrm{~h}$ after injection. Each value represents a pool of six animals. Positive controls were mouse macrophage lysate for iNOS and CD14, rat 
(e)

$\mathrm{eNOS}$
$140 \mathrm{kDa}$$\rightarrow$ Control + Control AG LPS LPS + AG Control AG LPS LPS + AG

(f)

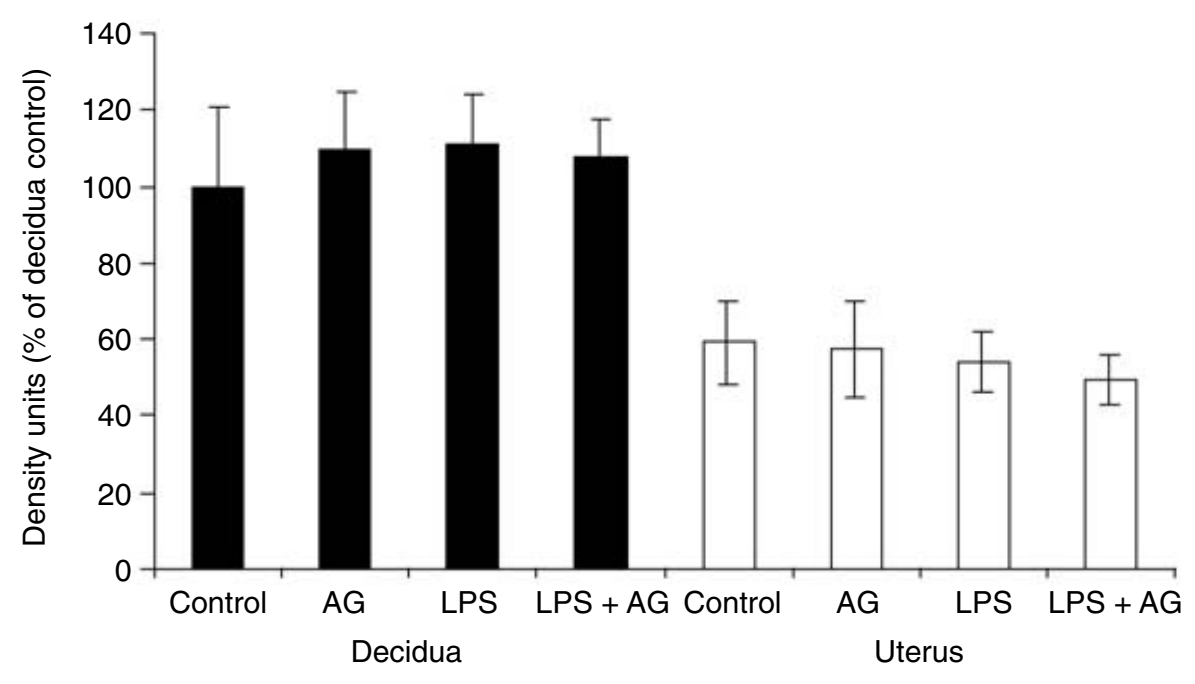

(g) Decidua Uterus

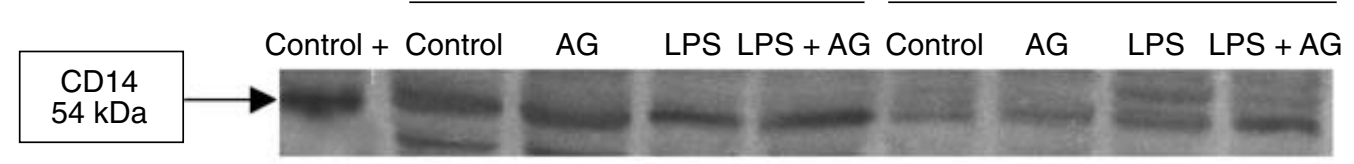

(h)

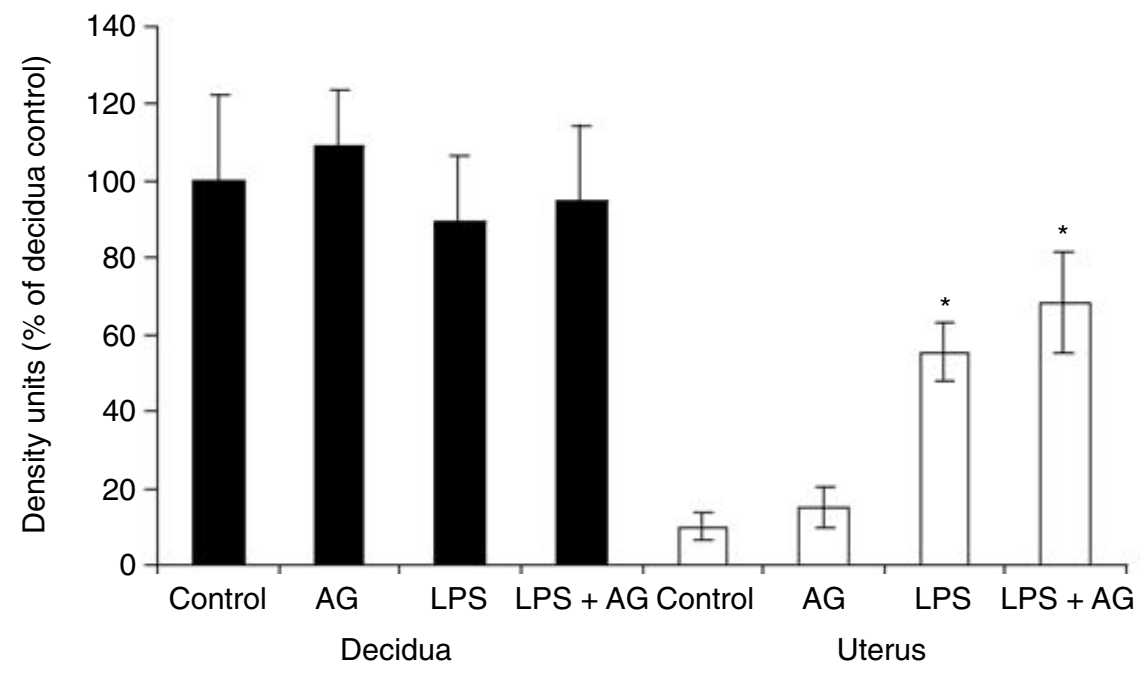

pituitary lysate for nNOS, and human endothelial cells for eNOS. Densitometric analysis of bands obtained for (b) iNOS, (d) nNOS, (f) eNOS and (h) CD14 was carried out using Sigma gel. Arbitrary density units expressed as percentages relative to decidua control values were plotted. Each bar corresponds to the mean of three different pools of six animals. *Values are significantly different from control values $(P<0.05)$. 

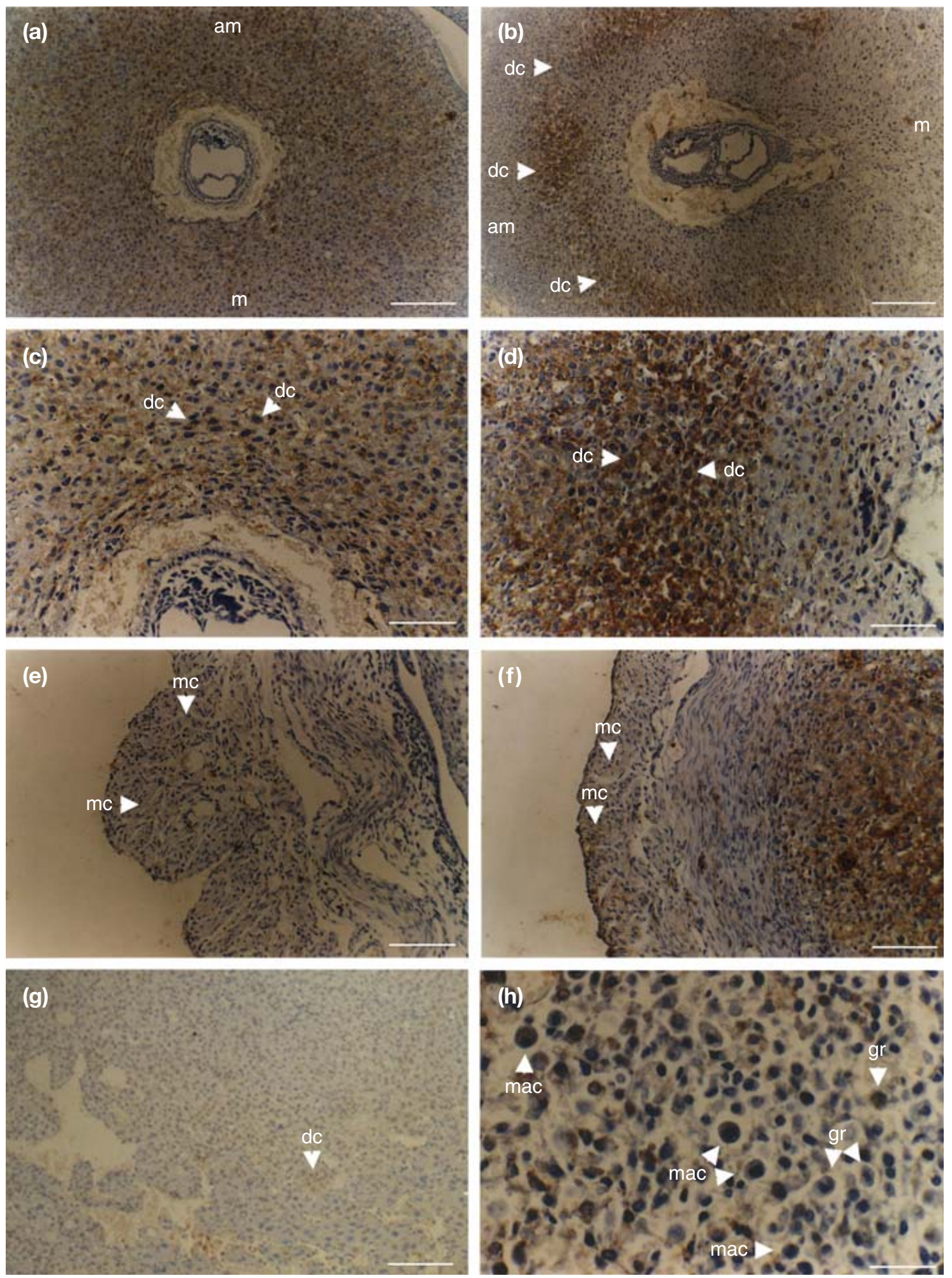

Fig. 5. Immunolocalization of inducible nitric oxide synthase (iNOS) in implantation sites of mice injected with PBS (control) or lipopolysaccharide (LPS). Balb/c female mice were injected on day 7 of pregnancy with $0.5 \mu \mathrm{g}$ LPS or PBS per g body weight and killed $6 \mathrm{~h}$ later. Sections were processed by the immunoperoxidase technique using anti-iNOS antibody. (a) Low power view showing moderate staining for iNOS in control decidua. (b) Low power view showing strong and localized staining for iNOS in decidual cells (dc) of mice injected with LPS. (c) Details of staining in decidua of control animals. (d) Details of staining in decidua of LPS animals. (e) iNOS staining was observed in myometrial cells $(\mathrm{mc})$ of the uterus of control animals. ( $f$ ) LPS augmented the iNOS staining 
increase in CD14 expression only in endometrial glands (Fig. 7b,d). The higher CD14 expression in the uterus of LPS-treated mice as detected by western blot analysis could be due to the fact that, as a result of the technique used, the endometrium did not separate from uterine tissue when the decidual tissue was extracted. The light staining for CD14 in the decidua does not correlate with the high amounts detected by western blot analysis. This discrepancy could be due to a lower sensitivity of immunohistochemistry as compared with western blot analysis. The slices from the tissues of animals treated with LPS had abundant infiltrates in the mesometrial decidua marked for CD14, and this identified them as macrophages and granulocytes (Fig. 7d inset).

\section{LPS and aminoguanidine effect on NOS activity (Experiment 3)}

LPS significantly increased NOS activity in the decidua $(P<0.001)$ and uterus $(P<0.001)$. Aminoguanidine partially blocked this increased activity in the decidua $(P<0.01)$ (Fig. 8a), and blocked it totally in the uterus $(P<0.001)$ (Fig. 8b). This could be explained by the fact that nNOS activity is not affected by aminoguanidine and its expression was increased by LPS only in the decidua, but an LPS-increased iNOS expression was observed in the decidua and uterus. NOS activity in the uterus and decidua of control animals was not affected by treatment with aminoguanidine, although in the uterus it appeared to have a non-significant inhibitory effect.

\section{Discussion}

The results of the present study show that on day 7 of normal pregnancy in mice, the isoforms iNOS, eNOS and $\mathrm{nNOS}$ are present in the decidua and uterus. The isoform iNOS is present in moderate amounts in the decidua as well as in myometrial cells and macrophages. Other authors have reported iNOS expression in decidual cells in early pregnancy (Purcell et al., 1999; Chwalisz and Garfield, 2000). This expression seems to be important in the processes of implantation and decidualization as aminoguanidine synergizes with the antiprogestagens in the inhibition of pregnancy establishment (Chwalisz et al., 1999). The uterine expression of the iNOS isoform is associated with the maintenance of the uterine quiescence (Dong et al., 1996; Farina et al., 2001).

The eNOS isoform appeared in the endothelium of the decidual lacunae and in the decidual and uterine vessels. Expression of eNOS in decidual vessels has also been reported by Purcell et al. (1999). Thus, eNOS expression can be very important for vasodilatation and platelet aggregation inhibition in the decidual vessels, which nourish the conceptus. The nNOS isoform appeared in decidual cells, and to a lesser extent in uterine cells. Purcell et al. (1999) also found this isoform in the decidua and myometrium during early pregnancy. The low expression of the nNOS isoform in the uterus is in agreement with other reports (Dong et al., 1996; Farina et al., 2001).

The LPS receptor, CD14, was abundant in the decidua and endometrial glands. Thus, these cells are capable of responding to LPS. This high expression may explain the increased sensitivity of the decidua to LPS. Decidual cells respond in vitro to LPS through the CD14 receptor (Arntzen et al., 1999). In control animals in the present study, basal NO production was observed in the uterus and decidua. Furthermore, an increase in NO production in the decidua was observed on day 7. Hunt et al. (1997) observed an increase in the number of macrophages and LGLs that were iNOS-positive during day 7 of pregnancy, which might explain the increased activity found in the present study.

Aminoguanidine did not have a significant effect on NOS activity in the uterus and decidua of control animals, although in the uterus it appeared to have a non-significant inhibitory effect. This finding could be explained by the fact that the uterus is one of the rare tissues that expresses iNOS even under non-stimulating conditions (Buhimschi et al., 1996; Nakaya et al., 1996). In the present study, aminoguanidine did not affect the resorption percentage or the number of sites when observed on days 8 and 12 . Some purple coloration was observed only on day 8 , probably due to thrombosis. Aminoguanidine did not have any effect on the size or morphology of the embryos, or the mass of the placenta (data not shown). This group of animals delivered normal fetuses. Chwalisz et al. (1999) showed that the treatment of rats on days 6-8 of pregnancy with L-NAME (NOS nonspecific inhibitor) or aminoguanidine had no significant effect on pregnancy (Chwalisz et al., 1999). In the present study, LPS at a dose of $0.5 \mu \mathrm{g}$ LPS per g body weight i.p. on day 7 of pregnancy produced $100 \%$ embryonic resorption at $24 \mathrm{~h}$ and fetus expulsion on day 9. This LPS dose produces systemic effects in the mother such as diarrhoea, piloerection and bent posture, but it is not fatal. Gendron et al. (1990) determined that LPS administered on day 7 of pregnancy also produces $100 \%$ resorption in the crossing of CFW/SW $\times$ DBA, with no systemic effects in the mother (Gendron et al., 1990), showing that the decidua, trophoblast and embryo are

in myometrial cells. (g) iNOS staining in mesometrial decidua was very weak in control animals. (h) LPS produced high fibrinolysis and infiltration of mesometrial decidua by iNOS positive macrophages (mac) and granulocytes (gr). am: antimesometrial decidua; m: mesometrial decidua. Scale bars represent (a,b) $200 \mu \mathrm{m},(\mathrm{c}-\mathrm{f}) 100 \mu \mathrm{m}$ and (g,h) $40 \mu \mathrm{m}$. 



Fig. 6. Immunolocalization of endothelial nitric oxide synthase (eNOS) and neuronal nitric oxide synthase (nNOS) in implantation sites of mice injected with PBS (control) or lipopolysaccharide (LPS). Balb/c female mice were injected on day 7 of pregnancy with $0.5 \mu \mathrm{g}$ LPS or PBS per g body weight and killed $6 \mathrm{~h}$ later. Sections were processed by the immunoperoxidase technique using anti-eNOS or anti-nNOS antibody. (a,b) Low power views showing staining for eNOS in endothelial cells of decidual arteries (da) of control and LPS-treated animals, respectively. (c,d) Details of staining for eNOS of decidual arteries in control and LPS-treated animals, respectively, showing no differences between treatments. (e) Low power view showing moderate staining for $\mathrm{nNOS}$ in the decidual cells (dc) and uterus of 

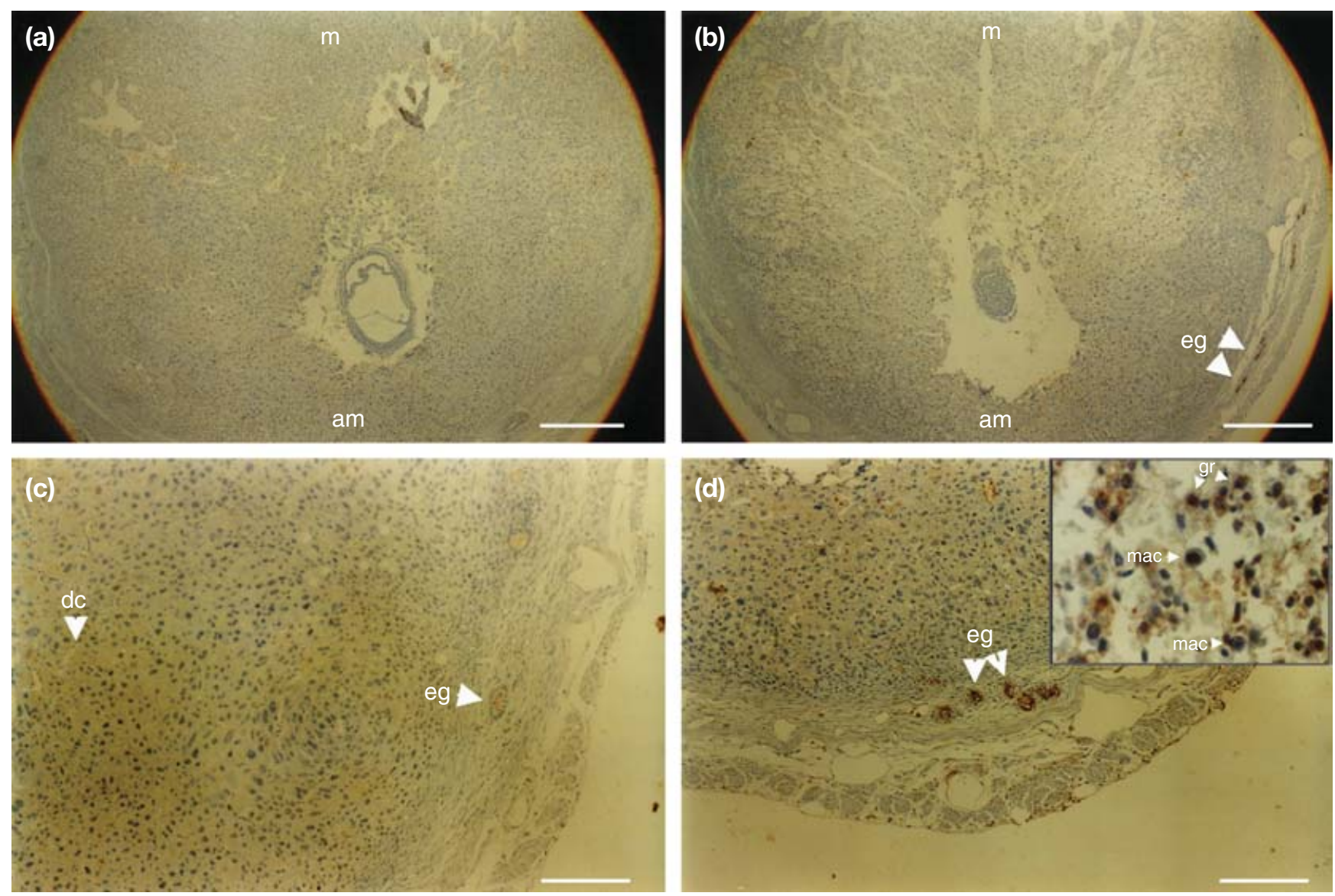

Fig. 7. Immunolocalization of CD14 (LPS receptor) in implantation sites of mice injected with PBS (control) or lipopolysaccharide (LPS). $\mathrm{Balb} / \mathrm{c}$ female mice were injected on day 7 of pregnancy with $0.5 \mu \mathrm{g}$ LPS or PBS per g body weight and killed $6 \mathrm{~h}$ later. Sections were processed by the immunoperoxidase technique using anti-CD14. (a,c) Low power and high power views, respectively, showing weak staining for CD14 in decidual cells (dc) and endometrial glands (eg) in control mice. (b,d) Low power and high power views showing strong staining for CD14 only in endometrial glands of LPS-treated animals. (d, inset) Infiltration of mesometrial decidua by CD14-positive macrophages (mac) and granulocytes (gr). am: antimesometrial decidua; m: mesometrial decidua. Scale bars represent (a,b) $200 \mu \mathrm{m} ;(\mathrm{c}, \mathrm{d})$ $100 \mu \mathrm{m}$; and (d, inset) $40 \mu \mathrm{m}$.

highly sensitive to pro-inflammatory molecules such as LPS.

The present study has shown that LPS produces total necrosis of the embryo and the decidua next to it after $24 \mathrm{~h}$. This necrotized decidua is expelled on day 9. However, another zone of the decidua that has not been totally necrotized is also present. This zone is highly infiltrated by granulocytes and LGLs. These infiltrated cells probably direct the expulsion of necrotized decidua, fibrinolysis and regeneration of tissue. In humans, LGLs direct the loss of decidua after delivery (Hunt, 1994). LPS causes an increase in NO production in the uterus and decidua, and this reaches a maximum at $6 \mathrm{~h}$ after injection. Production of $\mathrm{NO}$ in the decidua, $24 \mathrm{~h}$ after LPS injection, is undetectable and thus lower than in the control, possibly as a result of total decidua necrosis. The maximum production of $\mathrm{NO}, 6 \mathrm{~h}$ after LPS injection, has also been reported in other tissues (Salter et al., 1991). The present study has shown that this increase in $\mathrm{NO}$ production is accompanied by an increase in iNOS expression in the uterus and decidua, and an increase in nNOS expression in the decidua only. LPS does not produce any variation in the amount of expression or in the

control animals. (f) Low power view showing strong staining for nNOS in the decidua but not the uterus of LPS-treated animals. (g) In control animals, nNOS staining was observed in decidual cells and weaker staining was observed in myometrial cells (mc). (h) LPS augmented nNOS staining in decidual cells, but did not alter the staining of uterine cells. am: antimesometrial decidua; m: mesometrial decidua. Scale bars represent $(a, b, e, f) 200 \mu \mathrm{m}$ and (c,d,g,h) $100 \mu \mathrm{m}$. 
(a)

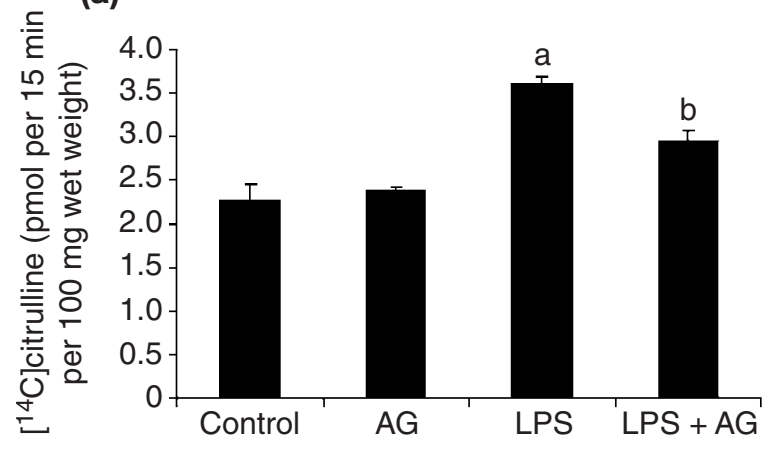

(b)

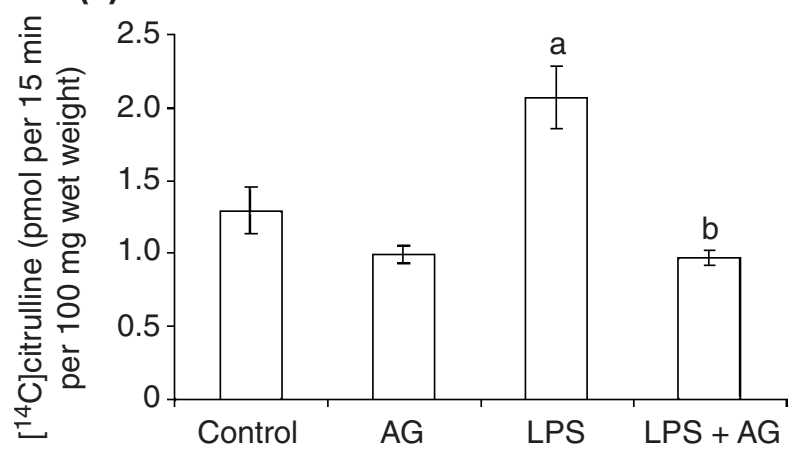

Fig. 8. In vivo effect in mice of aminoguanidine (AG), lipopolysaccharide (LPS) and LPS plus AG on nitric oxide synthase (NOS) activity in (a) the decidua and (b) the uterus (Expt 3 of Materials and Methods). Briefly, BALB/c female mice were injected on day 6 or day 7 of pregnancy with PBS (control), AG, LPS or LPS plus AG, and killed $6 \mathrm{~h}$ after injection. Values are mean \pm SEM $(n=6)$. (a) ${ }^{a}$ Value is significantly different from control $(P<0.001)$; ${ }^{b}$ value is significantly different from value for LPS-treated mice $(P<$ 0.01). (b) ${ }^{a}$ Value is significantly different from control $(P<0.001)$; ${ }^{b}$ value is significantly different from value for LPS-treated mice $(P<0.001)$

localization of the eNOS isoform. Immunohistochemistry has shown that LPS increases iNOS expression in decidual cells and causes infiltration of the mesometrial decidua by iNOS-positive macrophages and granulocytes. These infiltrated cells are also CD14positive. These leucocytes are responsible for the high fibrinolysis observed in mesometrial decidua. Other authors have determined that infiltration and macrophage activation in the decidua is crucial in the process of LPS-induced resorption (Gendron et al., 1990; Haddad et al., 1997; Wang et al., 1998). Others (Chen et al., 2001; Acarin et al., 2002; Greenacre et al., 2002) have also reported a role for granulocytes and macrophages expressing iNOS in the mechanism of tissue damage in different inflammation models. An increase in iNOS expression caused by LPS has also been found in myometrial cells in rats and pigs (Nakaya et al., 1996; Jana et al., 2001).

The present study has determined that LPS increases nNOS expression in the decidua but not in the uterus, indicating that $\mathrm{nNOS}$ can be induced under certain conditions. In the rat cervix, there is an increase in nNOS expression during delivery that has not been observed in the uterus (Buhimischi et al., 1996). Cella et al. (2001) determined that LPS induces nNOS expression in the rat uterus.

In addition, the present study has shown that LPS increases CD14 expression in endometrial glands only. This finding may be the result of an amplification of the inflammatory response. Jiang et al. (2001) also observed the induction of CD14 expression in liver cells of rats during endotoxic shock. In the mesometrial decidua of LPS-injected animals, infiltrates marked for CD14 were present, and this identified them as macrophages and granulocytes. The NO produced by the macrophages, granulocytes and tissue cells can be a powerful cytotoxic weapon against bacteria, but may also damage tissue cells (Ward, 1988; Fang, 1997).

The effect of aminoguanidine was examined to test the hypothesis that $\mathrm{NO}$ is important in the physiopathology of embryonic resorption caused by LPS. Aminoguanidine totally inhibited embryonic resorption on days 8 and 12 of pregnancy. The female rats treated simultaneously with LPS and aminoguanidine had similar resorption percentages to those of the control group and none of them expelled her fetus. Thus, NO fulfils an essential pathological role in LPS-induced embryo resorption. These findings agree with those of Athanassakis et al. (1999), who also found an inhibitory effect of aminoguanidine on LPS-induced embryonic resorption. Aminoguanidine at the dose used in the present study inhibited NOS activity stimulated by LPS in the uterus and in the decidua. In addition, aminoguanidine significantly inhibited LPS-induced leucocyte infiltration, and this could explain its inhibitory effect on resorption. Fibrinolysis was also inhibited by aminoguanidine because the extracellular matrix was less damaged, but this was not quantified. The inhibition of infiltration by aminoguanidine was not accompanied by lower iNOS, nNOS, eNOS and CD14 expression in the uterus and decidua, as variations in the western blot band intensity were not observed. The inhibition of infiltration may be due to lower NO production, which results in less tissue damage and requires fewer leucocytes, that is, acute inflammation positive feedback circuits are shortened. Baatz and Pleyer (2001) showed that aminoguanidine inhibits leucocyte infiltration in the iris in LPS-induced uveitis. Other iNOS inhibitors were able to inhibit neutrophil infiltration in other models of inflammation (Chen et al., 2001; Greenacre et al., 2002). In addition, it is possible that the inhibition of NO production affects the synthesis of other inflammatory mediators such as prostaglandins, the synthesis of which 
may be regulated by NO (Salvemini et al., 1993; Franchi et al., 1994; Ribeiro et al., 1999).

In summary, the present study has demonstrated that LPS produces embryonic resorption followed by fetal expulsion and that NO produced by iNOS plays a key role in this process. As the administration of L-NAME (non-specific inhibitor of NOS) in pregnant and infected rats increases mortality rate (Nowicki et al., 1997), an iNOS-specific inhibitor such as aminoguanidine may be tried in septic abortion because it does not abolish all NO synthesis necessary for implantation, decidualization, vasodilatation of decidual, placental and uterine vessels and myometrial relaxation.

This work was supported by grant PLACIRH PRE-038/2000, grant PICT 98 Proyecto 05-04426 and grant Carrillo-Oñativia (Ministerio de Salud de la Nación). The authors thank R. Morales and A. I. Casella for their technical assistance.

\section{References}

Acarin L, Peluffo H, Gonzalez B and Castellano B (2002) Expression of inducible nitric oxide synthase and cyclooxygenase-2 after excitotoxic damage to the immature rat brain Journal of Neuroscience Research $\mathbf{6 8}$ 745-754

Ariel I, Hochberg A and Shochina M (1998) Endothelial nitric oxide synthase immunoreactivity in early gestation and in trophoblastic disease Journal of Clinical Pathology 51 427-431

Arntzen KJ, Egeberg K, Rahimipoor S, Vatten L and Austgulen R (1999) LPS mediated production of IL-1, $\mathrm{PGE}_{2}$ and $\mathrm{PGF}_{2 \alpha}$ from term decidua involves tumor necrosis factor and tumor necrosis factor receptor p55 Journal of Reproductive Immunology 45 113-125

Athanassakis I, Aifantis I, Ranella A, Giouremou K and Vassiliadis S (1999) Inhibition of nitric oxide production rescues LPS-induced fetal abortion in mice Nitric Oxide 3 216-224

Baatz H and Pleyer U (2001) Modulation of leukocyte-endothelium interaction by nitric oxide synthase inhibitors: effects on leukocyte adhesion in endotoxin-induced uveitis Inflammation Research 50 534-543

Bradford M (1976) A rapid and sensitive method for the quantification of microgram quantities of protein utilizing the principle of protein-dye binding Analytical Biochemistry 72 248-254

Bredt DS and Snyder SH (1989) Nitric oxide mediates glutamate linked enhancement of cGMP levels in the cerebellum Proceedings National Academy of Sciences USA 66 9030-9033

Buhimschi I, Ali M, Jain V, Chwalisz K and Garfield RE (1996) Differential regulation of nitric oxide in the rat uterus and cervix during pregnancy and labour Human Reproduction 11 1755-1766

Cella M, Ogando D, Farina M, Ribeiro ML and Franchi AM (2001) El lipopolisacárido aumenta la síntesis de óxido nítrico vía dos isoformas de la NOS: nNOS e iNOS en útero de rata ovariectomizada Reproducao \& Climaterio 1615 (Abstract)

Chaouat G, Menu E, Clark DA, Dy M, Minkowski M and Wegmann TG (1990) Control of fetal survival in CBA $\times$ DBA/2 mice by lymphokine therapy Journal of Reproduction and Fertility $89447-458$

Chen LW, Hsu CM, Wang JS, Chen HL and Chen JS (2001) Inhibition of inducible nitric oxide synthase (iNOS) prevents lung neutrophil deposition and damage in burned rats Shock 15 151-156

Chwalisz K and Garfield RE (2000) Role of nitric oxide in implantation and menstruation Human Reproduction 15 96-111

Chwalisz K, Winterhager E, Thienel T and Garfield RE (1999) Synergistic role of nitric oxide and progesterone during the establishment of pregnancy in the rat Human Reproduction 14 542-552

Dong YL, Gangula PR and Yallampalli C (1996) Nitric oxide synthase isoforms in the rat uterus: differential regulation during pregnancy and labour Journal of Reproduction and Fertility 107 249-254
Duclos AJ, Haddad EK, Chalifour LE and Baines MG (1996) Embryo infiltration by maternal macrophages is associated with selective expression of proto-oncogenes in a murine model of spontaneous abortion Biology of Reproduction 54 1088-1095

Fang FC (1997) Mechanisms of nitric oxide-related antimicrobial activity Journal of Clinical Investigation 99 2818-2825

Farina M, Ribeiro ML and Franchi A (2001) Nitric oxide synthases in pregnant uterus Reproduction 121 403-407

Franchi AM, Chaud M, Rettori V, Suburo A, McCann SM and Gimeno M (1994) Role of nitric oxide in eicosanoid synthesis and uterine motility in estrogen-treated rat uteri Proceedings National Academy of Sciences USA 91 539-543

Gendron RL, Nestel FP, Lapp WS and Baines MG (1990) Lipopolysaccharide induced fetal resorption in mice is associated with the intrauterine production of tumor necrosis factor alpha Journal of Reproduction and Fertility 90 395-402

Greenacre SA, Rocha FA, Rawlington A, Meinerikandathevan S, Poston RN, Ruiz E, Halliwell B and Brain SD (2002) Protein nitration in cutaneous inflammation in the rat: essential role of inducible nitric oxide synthase and polymorphonuclear leukocytes British Journal of Pharmacology 136 985-994

Grisham MB, Johnson GG and Lancaster JR, Jr (1996) Quantification of nitrate and nitrite in extracellular fluids Methods in Enzymology 268 $237-246$

Grisham MB, Jourd'heuil D and Wink DA (1999) Nitric oxide I. Physiological chemistry of nitric oxide and its metabolites: implications in inflammation American Journal of Physiology 276 315-321

Haddad EK, Duclos AJ and Baines MG (1995) Early embryo loss is associated with local production of nitric oxide by decidual mononuclear cells Journal of Experimental Medicine 182 1143-1151

Haddad EK, Duclos AJ, Antecka E, Lapp WS and Baines MG (1997) Role of interferon- $\gamma$ in the priming of decidual macrophages for nitric oxide production and early pregnancy loss Cellular Immunology $\mathbf{1 8 1}$ 68-75

Hunt JS (1994) Immunologically relevant cells in the uterus Biology of Reproduction 50 461-466

Hunt JS, Miller L, Vassmer D and Croy BA (1997) Expression of inducible nitric oxide synthase gene in mouse uterine leukocytes and potential relationships with uterine function during pregnancy Biology of Reproduction $\mathbf{5 7}$ 827-836

Jana B, Andronowska A and Kucharski J (2001) Immunoreactivity of iNOS in porcine uterus after infusions of Escherichia coli endotoxin Folia Histochemica et Cytobiologica 39 177-178

Jiang J, Xie G, Chen Y, Liu D, Qiu J, Zhou J, Zhu P and Wang Z (2001) Intra-hepatic expression of scavenger receptor and CD14 and their relationship with local inflammatory responses in endotoxemia in mice Shock 16 75-80

Karima R, Matsumoto S, Higashi H and Matsushima K (1999) The molecular pathogenesis of endotoxic shock and organ failure Molecular Medicine Today 5 123-132

Misko TP, Moore WM, Kasten TP, Nickols GA, Corbett JA, Tilton RG, McDaniel ML, Williamson JR and Currie MG (1993) Selective inhibition of inducible nitric oxide synthase by aminoguanidine European Journal of Pharmacology 233 119-125

Nakaya Y, Yamamoto S, Hamada Y, Kamada M, Aono T and Niwa M (1996) Inducible nitric oxide synthase in uterine smooth muscle Life Science 58 249-255

Nowicki B, Fang L, Singhal J, Nowicki S and Yallampalli C (1997) Lethal outcome of uterine infection in pregnant but not in non-pregnant rats and increased death rate with inhibition of nitric oxide American Journal of Reproductive Immunology 38 309-312

Purcell TL, Given R, Chwalisz K and Garfield RE (1999) Nitric oxide synthase distribution during implantation in the mouse Molecular Human Reproduction 5 467-475

Raghupathy R (1997) Th1-type immunity is incompatible with successful pregnancy Immunology Today 18 478-482

Ribeiro ML, Perez Martinez S, Farina M, Ogando D, Gimeno M and Franchi AM (1999) The effect of epidermal growth factor on prostaglandin synthesis of oestrogenized rat uterus is mediated by nitric 
oxide Prostaglandins, Leukotrienes and Essential Fatty Acids 61 353358

Salter M, Knowles RG and Moncada S (1991) Widespread tissue distribution, species distribution and changes in activity of $\mathrm{Ca}^{2+}$ dependent and $\mathrm{Ca}^{2+}$-independent nitric oxide synthases FEBS Letters 291 145-149

Salvemini D, Misko TP, Masferrer JL, Seibert K, Currie MG and Needleman P (1993) Nitric oxide activates cyclooxygenase enzymes Proceedings National Academy of Sciences USA $907240-7244$

Sladek SM, Magness RR and Kirk PC (1997) Nitric oxide and pregnancy American Journal of Physiology 272 441-463
Wang YY, Tawfik O and Wood GW (1998) Endotoxin induced abortion in mice is mediated by activated fetal macrophages Journal of Leukocyte Biology 63 40-50

Ward PA, Warren JS and Johnson KJ (1988) Oxygen radicals, inflammation and tissue injury Free Radical Biological Medicine 5 403-408

Received 27 May 2002.

First decision 7 August 2002

Revised manuscript received 4 September 2002.

Accepted 19 September 2002. 